1. MBBS, MRCOG, FRCS Professor Obs/Gynae Military Hospital, Rawalpindi.

2. MBBS, FCPS

Senior Registrar Obs/Gynae Shifa College of Medicine, Islamabad.

3. MBBS Final Year Student FUMC RWP.

4. MBBS

PGT Obs/Gynae

Military Hospital, Rawalpindi.

5. MBBS

PGT Obs/Gynae

Military Hospital, Rawalpindi.

6. MBBS, MCPS, FCPS

Assistant Professor Obs/Gynae

Military Hospital, Rawalpindi.

Correspondence Address:

Dr. Abeera Choudry

Professor Obs/Gynae

Military Hospital, Rawalpindi.

abeera_choudry@yahoo.com

Article received on:

13/06/2020

Accepted for publication:

01/12/2020

\section{Frequency of meconium stained liquor in low risk laboring women and its effect on perinatal outcome in a tertiary care hospital.}

\begin{abstract}
Abeera Choudry', Maria Habib ${ }^{2}$, Zaineb Shamim ${ }^{3}$, Syeda Zubda Batool', Marium Haroon ${ }^{5}$, Uzma Rehman Kallu ${ }^{6}$

ABSTRACT... Objective: To evaluate the frequency of meconium stained liquor (MSL) in low risk women and its effect on perinatal outcomes. Study Design: Prospective Case Control study. Setting: Department of Obstetrics and Gynecology Military Hospital, Rawalpindi. Period: January to August 2017. Material \& Methods: Distribution of MSL was studied according to its grade. Data included demographic profile, mode of delivery, intrapartum factors and neonatal outcomes. Descriptive statistics and chi-square were used for analysis. Results: Frequency of MSL was 376 (3.65\%) among 10,281 deliveries during study period. A total of 752 women were included in the study which were divided into cases and controls. Nulliparity and advanced gestational age were significantly associated with MSL. Distribution of grade of meconium was $20.5 \%, 56.4 \%$ and $23.1 \%$ for grade I, II and III MSL. Breech presentation, fetal heart rate abnormalities and cesarean section were significantly associated with MSL. Low apgar score at 1 and 5 minutes, Neonatal intensive unit care admissions and fetal complications had positive correlation with MSL. Frequency of meconium aspiration syndrome (MAS) was $16.4 \%$, birth asphyxia $5.31 \%$ and respiratory distress syndrome (RDS) $1.32 \%$ amongst all the cases of MSL. However, frequency of MAS, birth asphyxia and RDS was $0.6 \%, 0.19 \%, 0.02 \%$ in general obstetric population. Neonatal mortality was $29 \%$ in MAS, $3.4 \%$ in MSL and $0.12 \%$ in general population. Adverse neonatal outcomes had positive correlation with increasing grade of meconium. Conclusion: There is a significant frequency of meconium stained liquor even in low risk women. MSL is significantly associated with increased cesarean section rates and adverse neonatal outcomes.
\end{abstract}

Key words: $\quad$ Adverse Pregnancy Outcomes, Frequency, Meconium Aspiration Syndrome.

Article Citation: Choudry A, Habib M, Shamim Z, Batool SZ, Haroon M, Kallu UR. Frequency of meconium stained liquor in low risk laboring women and its effect on perinatal outcome in a tertiary care hospital. Professional Med J 2021; 28(7):936-943. https://doi.org/10.29309/TPMJ/2021.28.07.5194

\section{INTRODUCTION}

The word "Meconium" has been taken from Greek word which was used for addictive materials as meconium leads to fetal quiescence during antenatal or intrapartum period. Meconium is secreted by digestive tract which consists of mucus, cellular debris and various secretions of gastrointestinal tract. ${ }^{1}$ The meconium stained liquor (MSL) complicates $12-16 \%$ of all pregnancies. $^{2}$

Various risk factors for MSL have been identified which includes nulliparity, hypertensive disorders of pregnancy, reduced liquor, placental pathologies, intrauterine infection, maternal intake of addictive substances and postdates pregnancy. The main causes of MSL are maturity of fetal digestive system and fetal hypoxia. ${ }^{3}$

MSL has been well studied for its association with pathological cardiotocography, instrumental vaginal deliveries (IVD), cesarean section (CS), neonatal resuscitation, admissions to neonatal intensive care unit (NICU) due to respiratory distress syndrome (RDS), meconium aspiration syndrome (MAS), birth asphyxia and early neonatal death (ENND). ${ }^{3,4}$ Meconium acts by blocking air passages, reduces surfactant by damaging alveoli and causes local inflammation \& hypoxia. $^{5}$

The most frequent complication of MSL is MAS. 
A recent study conducted by Choi $W$ et al over the period of 6 years, found that incidence of MAS was $10.6 \%$ in cases of MSL. Distribution of mild, moderate and severe MAS was $81.7 \%, 5.6 \%$ and $12.7 \%$ amongst all the cases of MAS. ${ }^{6}$ Back in 2000, the reported prevalence of MAS was $0.20 \%$ to $0.54 \%$ in all deliveries and $1 \%$ to $6.8 \%$ in deliveries with MSL. ${ }^{7}$ Literature from 1990 to 1998 has reported a mortality of $4.6 \%$ from MAS. ${ }^{8}$ During period of 1995-2001, a national study in United States highlighted that MAS has positive correlation with advancing gestation, from $0.10 \%$ at 37 weeks to $0.31 \%$ at 41 weeks. $^{9}$

MAS can be prevented by expediting delivery along with continuous fetal heart rate monitoring once MSL is diagnosed and by endotracheal suctioning of the neonate immediately after birth. The cause of mortality in MAS is respiratory failure due to pulmonary hypertension. Various treatment modalities for neonates with MAS are available which includes mechanical ventilation to prevent from respiratory failure, nitric oxide for better oxygenation and surfactant. These treatment modalities are very expensive and not easily accessible in all the centres. ${ }^{10}$

Though there is lack of facility of fetal blood sampling in developing countries like Pakistan but the availability of cardiotocography (CTG) for fetal heart rate monitoring has improved neonatal outcomes. Considering MSL to be a very common problem encountered in labour ward and its association with neonatal morbidity and mortality, this study was conducted to evaluate the frequency of MSL in low risk women and its effect on perinatal outcomes in a setup where facilities for monitoring of fetal heart rate are available and deliveries are conducted by trained birth attendants and, where all the neonates with MSL are attended by pediatricians. The characteristic feature of this study was that all the women with known risk factors for MSL like maternal hypertension/renal//autoimmune disease/obstetrics cholestatsis etc and known fetal anomalies were excluded so as to find the frequency of MSL in extremely low risk women. It is generally thought that isolated MSL is a sign of fetal gut maturity with minimal association with fetal comprise. ${ }^{8}$ We wanted to investigate this sub group of MSL.

\section{MATERIAL \& METHODS}

After taking ethical approval from hospital's ethics committee, this prospective observational study was conducted in the department of Obstetrics and Gynaecology Military hospital, Rawalpindi between $1^{\text {st }}$ Jan to $31^{\text {st }}$ Aug, 2017 over the period of 8 months. All the deliveries with meconium stained liquor (MSL) served as cases. Cases were compared with random group matched with same gestational age from deliveries conducted on the same day with clear liqour. Exclusion criteria was previous cesarean section, any maternal risk factors for example diabetes/hypertension/renal/ cardiac/autoimmune disease etc, known fetal anomalies which were confirmed on 18-22 weeks anomaly scan. Distribution of MSL was studied according to its grade. Grade I MSL; watery and light yellow green, grade II MSL; watery but deep green and MSL III as thick dark green like spinach soup. A researcher trainee approached all the patients who fulfilled the inclusion criteria and after explaining objectives of the study, a verbal informed consent was taken. Data included demographic profile [age, parity, gestational age (GA)], mode of delivery [spontaneous vaginal delivery (SVD), IVD, emergency lower segment cesarean section (Em.LSCS) or elective lower segment cesarean section (El.LSCS)], intrapartum factors [induced versus spontaneous labour, cephalic versus breech presentation, duration of rupture of membranes, CTG] and neonatal outcomes [apgar score at 1 and 5 minutes, birth weight, NICU admissions, any fetal complications like MAS, birth asphyxia, RDS and ENDD]. All the information was entered on predesigned questionnaire proforma. Decision of mode of delivery was taken by senior obstetrician once MSL was found after artificial rupture of membranes (ARM). CTG trace was taken for initial 10 minutes for all the babies who were diagnosed with MSL after ARM. Then fetal heart rate was monitored by intermittent auscultation till delivery for those getting delivered vaginally. Those delivered by El.LSCS and MSL was found incidentally, their last CTG trace before LSCS was entered in proforma. Pediatrician was called at 
the time of delivery for babies delivered with MSL. All the babies with MSL were shifted to NICU for observation for at least 6 hours, and admitted if required. The final diagnosis of any neonatal complications was made by senior pediatrician.

Data were stored and analyzed using statistical package for social sciences (SPSS) version 23.0. Count and percentages were computed for demographic profile, frequency of meconium and its distribution according to grade, intrapartum factors and neonatal outcomes. Pearson chisquare test was used to analyse the association of various parameters with meconium and its grade. P-value less than 0.05 were considered statistically significant.

\section{RESULTS}

Total number of deliveries conducted during the study period were 10,281. Frequency of MSL was 376 (3.65\%).

A total of 752 women were included in the study. Out of which, 376 women in MSL group were compared with 376 randomly selected controls, matched with gestational age.

Demographic profile of the study participants is shown (Table-I). In brief, more than seventy percent participants belonged to a age group of 20-30 years. Nulliparity predominated in MSL and had significant association with it. Many participants had a gestational age (GA) more than 39 weeks.

Majority of the cases had grade II MSL, followed by grade III and grade I as shown (Figure-1).

$(n=376)$

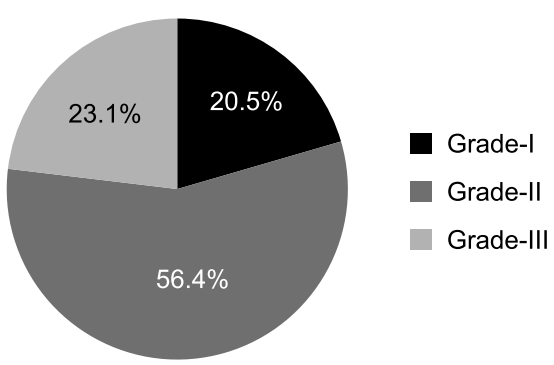

Figure-1. Distribution of grade of MSL.
Fetal presentation was cephalic in more than ninety percent of the participants in both groups. However, breech presentation was predominating in MSL. Type of labour (spontaneous versus induced), duration of rupture of membranes and total duration of labour had no correlation with MSL $(P>0.05)$. Suspicious and pathological CTG was seen more in MSL $(P<0.05)$. More than half of the participants delivered via Em.LSCS in MSL group and it had significant association with operative delivery (Table-II).

Low apgar score at 1 and 5 minutes, NICU admissions, fetal complications in the form of MAS, birth asphyxia, RDS and ENND had positive correlation with MSL. Frequency of MAS was $16.4 \%$, birth asphyxia $5.31 \%$ and RDS $1.32 \%$ amongst all the cases of MSL. However in general obstetric population, frequency of MAS was $0.6 \%$, birth asphyxia $0.19 \%$, RDS $0.02 \%$. Birth weight was not associated with MSL. Neonatal mortality was $29 \%$ in MAS, $3.4 \%$ in MSL and $0.12 \%$ in general obstetric population (Table-III).

Neonatal outcomes according to grade of meconium are shown (Table-IV). In brief, Apgar score at 1 minute had inverse relationship with grade of meconium $(P<0.01)$. At 5 minutes, apgar score improved in all the neonates with grade I MSL while few had low apgar score in grade II and III MSL $(P=0.01)$. Bith weight had no association with MSL $(P=0.15)$. Fetal complications were more in grade II and III MSL as compared to grade I MSL $(P<0.05)$. None of the ENND were seen in grade I MSL. However with increasing grade of MSL, number of ENND increased $(P<0.01)$

\section{DISCUSSION}

Presence of meconium in liqour is a cause of concern for healthcare professionals because of its association with fetal distress, though it also reflects fetal maturity. ${ }^{11}$ It is generally believed that MSL is associated with adverse perinatal outcomes.

The present study conducted on 10,281 deliveries has revealed that the frequency of MSL was $3.65 \%$ after excluding all the high risk factors for MSL, which is comparable to other studies. 


\begin{tabular}{|c|c|c|c|c|}
\hline \multirow{3}{*}{\multicolumn{2}{|c|}{ Parameters }} & \multicolumn{2}{|c|}{ Meconium Stained Liquor } & \multirow{3}{*}{ P-Value } \\
\hline & & \multirow{2}{*}{$\begin{array}{c}\text { Control } \\
\mathrm{N} \%\end{array}$} & \multirow{2}{*}{$\begin{array}{c}\text { Cases (MSL) } \\
\text { N \% }\end{array}$} & \\
\hline & & & & \\
\hline \multirow{4}{*}{ Maternal Age (years) } & $<20$ & $15(4.0)$ & $14(3.7)$ & \multirow{4}{*}{0.74} \\
\hline & $20-30$ & $268(71.3)$ & $265(70.5)$ & \\
\hline & $30-40$ & 90 (23.9) & $96(25.5)$ & \\
\hline & $>40$ & $3(.8)$ & $1(.3)$ & \\
\hline \multirow{5}{*}{ Parity } & 0 & $67(17.8)$ & $159(42.3)$ & \multirow{5}{*}{$<0.01^{*}$} \\
\hline & 1 & $134(35.6)$ & $100(26.6)$ & \\
\hline & 2 & $90(23.9)$ & $59(15.7)$ & \\
\hline & 3 & $37(9.8)$ & $32(8.5)$ & \\
\hline & 4 & $48(12.8)$ & $26(6.9)$ & \\
\hline \multirow{6}{*}{ GA (weeks) } & $>40$ & $80(21.3)$ & $80(21.3)$ & \multirow{6}{*}{1} \\
\hline & $39-39+6$ & $109(29.0)$ & $109(29.0)$ & \\
\hline & $38-38+6$ & $93(24.7)$ & $93(24.7)$ & \\
\hline & $37-37+6$ & $56(14.9)$ & $56(14.9)$ & \\
\hline & $<37$ & $38(10.1)$ & $38(10.1)$ & \\
\hline & $<20$ & $5(4.0)$ & $14(3.7)$ & \\
\hline
\end{tabular}

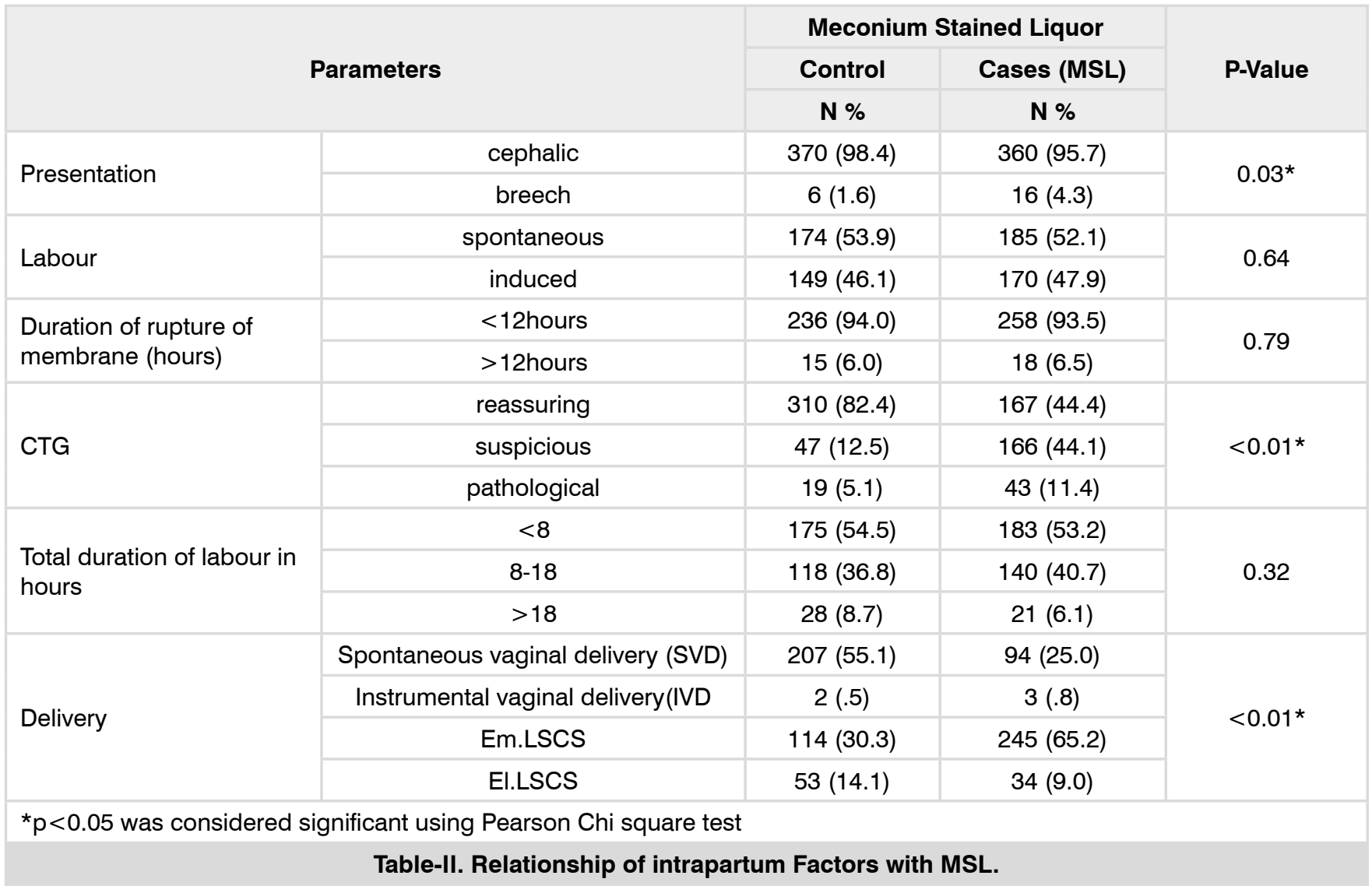




\begin{tabular}{|c|c|c|c|c|}
\hline \multirow{3}{*}{\multicolumn{2}{|c|}{ Parameters }} & \multicolumn{2}{|c|}{ Meconium Stained Liquor } & \multirow{3}{*}{ P-Value } \\
\hline & & \multirow{3}{*}{$\begin{array}{c}\text { Control } \\
\text { N \% } \\
314(83.5)\end{array}$} & \multirow{3}{*}{$\begin{array}{c}\text { Cases (MSL) } \\
\mathbf{N} \% \\
160(42.6)\end{array}$} & \\
\hline & & & & \\
\hline \multirow{3}{*}{ Apgar score $1 \mathrm{~min}$} & $>7$ & & & \multirow{3}{*}{$<0.01 *$} \\
\hline & $4-7$ & $58(15.4)$ & $206(54.8)$ & \\
\hline & $<4$ & $4(1.1)$ & $10(2.7)$ & \\
\hline \multirow{3}{*}{ Apgar score $5 \mathrm{~min}$} & $>7$ & $370(98.4)$ & $355(94.4)$ & \multirow{3}{*}{$0.01 *$} \\
\hline & $4-7$ & $6(1.6)$ & $19(5.1)$ & \\
\hline & $<4$ & $0(.0)$ & $2(.5)$ & \\
\hline \multirow{3}{*}{ Birth Weight (Kg) } & $<2.5 \mathrm{~kg}$ & $9(2.4)$ & $19(5.1)$ & \multirow{3}{*}{0.15} \\
\hline & $2.5-4 \mathrm{~kg}$ & $365(97.1)$ & $355(94.4)$ & \\
\hline & $>4 \mathrm{~kg}$ & $2(.5)$ & $2(.5)$ & \\
\hline \multirow{2}{*}{ NICU Admission } & yes & $46(12.2)$ & $194(51.6)$ & \multirow{2}{*}{$<0.01^{*}$} \\
\hline & no & $330(87.8)$ & $182(48.4)$ & \\
\hline \multirow{4}{*}{$\begin{array}{l}\text { Any Fetal } \\
\text { Complication }\end{array}$} & MAS & $0(.0)$ & $62(68.1)$ & \multirow{4}{*}{$<0.01 *$} \\
\hline & Birth asphyxia & $13(48.1)$ & $20(22.0)$ & \\
\hline & RDS & $2(7.4)$ & $5(5.5)$ & \\
\hline & other & $12(44.4)$ & $4(4.4)$ & \\
\hline \multirow{2}{*}{ Outcome } & recovered & $374(99.5)$ & $363(96.5)$ & \multirow{2}{*}{$<0.01 *$} \\
\hline & ENND & $2(.5)$ & $13(3.5)$ & \\
\hline & $\begin{array}{r}{ }^{*} p<0.05 \text { was co } \\
\text { Table-III. } \mathrm{N}\end{array}$ & $\begin{array}{l}\text { gnificant } u \\
\text { :omes in } \mathrm{m}\end{array}$ & $\begin{array}{l}\text { on Chi square } \\
\text { tained liquor. }\end{array}$ & \\
\hline
\end{tabular}

\begin{tabular}{|c|c|c|c|c|c|}
\hline \multirow{3}{*}{\multicolumn{2}{|c|}{ Parameters }} & \multicolumn{3}{|c|}{ Grade } & \multirow{3}{*}{ P-Value } \\
\hline & & \multirow{3}{*}{$\begin{array}{c}\mathbf{I} \\
\mathbf{N} \% \\
54(70.1)\end{array}$} & \multirow{3}{*}{$\begin{array}{c}\text { II } \\
\text { N \% } \\
87(41.0)\end{array}$} & \multirow{3}{*}{$\begin{array}{c}\text { III } \\
\text { N \% } \\
19(21.8)\end{array}$} & \\
\hline & & & & & \\
\hline \multirow{3}{*}{ Apgar score $1 \mathrm{~min}$} & $>7$ & & & & \multirow{3}{*}{$<0.01 *$} \\
\hline & $4-7$ & $23(29.9)$ & $123(58.0)$ & $60(69.0)$ & \\
\hline & $<4$ & - & $2(0.9)$ & $8(9.2)$ & \\
\hline \multirow{3}{*}{ Apgar score $5 \mathrm{~min}$} & $>7$ & $77(100.0)$ & 202 (95.3) & $76(87.4)$ & \multirow{3}{*}{$<0.01 *$} \\
\hline & $4-7$ & - & $10(4.7)$ & $9(10.3)$ & \\
\hline & $<4$ & - & - & $2(2.3)$ & \\
\hline \multirow{4}{*}{ Any Fetal Complication } & MAS & $1(16.7)$ & $30(71.4)$ & $31(72.1)$ & \multirow{4}{*}{$0.025^{\star}$} \\
\hline & birth asphyxia & $3(50.0)$ & $8(19.0)$ & $9(20.9)$ & \\
\hline & RDS & $2(33.3)$ & $2(4.8)$ & $1(2.3)$ & \\
\hline & other & - & $2(4.8)$ & $2(4.7)$ & \\
\hline \multirow{2}{*}{ Outcome } & recovered & $77(100.0)$ & $208(98.1)$ & $78(89.7)$ & \multirow{2}{*}{$<0.01^{*}$} \\
\hline & ENND & - & $4(1.9)$ & $9(10.3)$ & \\
\hline
\end{tabular}

A population based French study on 132,884 newborns has shown frequency of MSL to be $7.93 \% .{ }^{12}$ Korean study has highlighted incidence of MSL as $4.99 \%$ amongst 14,666 deliveries. In other studies, its incidence varies between $4.0 \%$ to $16.5 \%$. $3,6,13,14,15$

Distribution of grade of meconium in our study was $20.5 \%, 56.4 \%$ and $23.1 \%$ for grade I, II and III MSL. Similar to our results, a study from Lahore on 250 cases of MSL has shown that grade II MSL was predominating (56\%) as compared to grade I (22\%) or grade III MSL (22\%). ${ }^{3}$ Sori DA et al found frequency of MSL as $25.2 \%, 39.7 \%$ and $35.1 \%$ from grade I to III. ${ }^{16}$

Vaghela HP et al proposed that maternal age has no correlation with MSL which is also demonstrable in our results as majority of the participants belonged to age group of $20-30$ 
years. ${ }^{17}$ According to Rao KS et al, nulliparity is significantly associated with $\mathrm{MSL}^{18}$ which is in line with our results. Published literature has revealed that incidence of MSL increases with advancing gestational age due to maturity of the fetal digestive system. ${ }^{19}$ Similar results were found in our study as majority of the participants with MSL had GA more than 39 weeks.

Dordević $M$ et al conducted a study on 282 breech deliveries and highlighted a significant association of MSL with breech presentation which is analogous to our results. ${ }^{20}$ Though cardiotocography is considered indeterminate, our study has shown that suspicious and pathological cardiotocography was seen more in MSL (55.5\%) as compared to clear liquor (17.6\%). Similarly, de Souza A et al and Frey HA et al have also found significant association of meconium with abnormalities in fetal heart rate pattern which causes increased neonatal morbidity. ${ }^{21,22}$

The present study has found no correlation of MSL with type of labour (spontaneous versus induced). This is in contrast to the Cochrane database review which highlighted increased meconium staining in induced labors (with oral misoprostol). ${ }^{23}$ This may be because in our study almost all the participants were induced with PGE2 instead of misoprostol. This could account for variance in findings. The association of duration of labour with MSL is conflicting. Sori DM et al found no correlation of MSL with duration of labour, which mirrored the results of our study. However, Lee KA et al conducted a study on 4376 women and highlighted that higher frequency of MSL was associated with prolonged duration of labour ( $1^{\text {st }}, 2^{\text {nd }}$ stage and total as well) and with increased duration of rupture of membranes. ${ }^{24}$ In contrast to these results, our study didn't show any association of MSL with duration of rupture of membranes. This needs to be evaluated in further studies with adjustment of confounding factors. Akin to other studies, Em.LSCS was the predominant mode to expedite delivery in our study. ${ }^{13,15,24,25}$

Our study has strengthened the results of previous studies that MSL is one of the important factors for depressed apgar scores. ${ }^{13,15,25,26,27}$ Similar to other studies, birth weight had no correlation with MSL. Higher NICU admissions in present study are in agreement with other studies. ${ }^{16,26,28}$

Frequency of MAS was $16.4 \%$, birth asphyxia $5.31 \%$, RDS $1.32 \%$ in our study. Rao KS et al found similar rates of MAS (12\%) but more cases of birth asphyxia were seen in his study $(21 \%) .{ }^{18}$ In a retrospective population based study by Fischer $\mathrm{C}$ et al, incidence of MAS ranged from $0.11 \%$ at 37 weeks to $0.49 \%$ at $42+$ weeks in general population which is comparable to our results (0.6\%). ${ }^{12}$ A local data of two studies from Lahore highlighted a high mortality rate with MAS (29\% and $32 \%$ ) which is parallel to our results $(29 \%)$. However, studies from developed countries has shown decreased neonatal mortality associated with MAS (7.9\%) which may be because of one to one care and advanced treatment modalities. ${ }^{12,29,30}$

Depressed apgar scores at 1 and 5 minutes and neonatal complications including ENND had positive correlation was increasing grade of MSL which is in accordance with other studies. ${ }^{16,31}$ Similarly, Kumari R et al in her study on 75 patients with MSL demonstrated poor neonatal outcomes with thick meconium. ${ }^{32}$

Despite limitations of non-availability of fetal scalp blood sampling, our study is strengthened by its large sample size, monitoring of fetal heart rate till delivery in all MSL cases, delivery by trained birth attendants, presence of pediatrician for endotracheal suctioning at birth and availability of mechanical ventilation in NICU. Moreover, a thorough association of various neonatal parameters has been evaluated with meconium in women with no known risk factors for MSL and this study has helped in predicting severity of neonatal outcomes according to grades of meconium.

\section{CONCLUSION}

Our study has highlighted that frequency of MSL is higher in even those women who had no risk factors for MSL. MSL is significantly associated with increased cesarean section rates and poor neonatal outcomes. Once meconium is detected, 
increased fetal surveillance, early delivery and neonatal expertise for endotracheal suctioning and ventilatory support (if required) can improve neonatal outcomes.

Copyright (

\section{REFERENCES}

1. Haiden N, Pimpel B, Kreissl A, Jilma B, Berger A. Does visceral osteopathic treatment accelerate meconium passage in very low birth weight infants? A prospective randomized controlled trial. PLoS One 2015; 10(4):e0123530.

2. Maymon E, Chaim W, Furman B, Ghezzi F, Shoham Vardi I, Mazor M. Meconium stained amniotic fluid in very low risk pregnancies at term gestation. Eur $\mathrm{J}$ Obstet Gynecol Reprod Biol. 1998; 80: 169-73.

3. Shaikh EM, Mehmood S, Shaikh MA. Neonatal outcome in meconium stained amniotic fluid- One year experience. J Pak Med Assoc. 2010; 60(9):711-14.

4. Kalis V, Turek J, Hudec A, Rokyta Z, Mejchar B. Meconium and postnatal neurologic handicaps. Ceska Gynecol. 2001; 66(5):369-377.

5. Usta IM, Zoorob D, Abu-Musa A, Naassan G, Nassar AH. Obstetric outcome of teenage pregnancies compared with adult pregnancies. Acta Obstet Gynecol Scand. 2008; 87(2):178-83. DOI:10.1080/00016340701803282.

6. Choi W, Jeong H, Choi SJ, Oh SY, Kim JS, Roh $\mathrm{CR}$ et al. Risk factors differentiating mild/moderate from severe meconium aspiration syndrome in meconium-stained neonates. Obstet Gynecol Sci. 2015; 58(1):24-31.

7. Yoder BA, Kirsch EA, Barth WH, Gordon MC. Changing obstetric practices associated with decreasing incidence of meconium aspiration syndrome. Obstetrics and Gynecology. 2002; 99(5):731-739.

8. Liu WF, Harrington T. Delivery room risk factors for meconium aspiration syndrome. American Journal of Perinatology. 2002; 19(7):367-378.

9. Zhang X, Kramer MS. Variations in mortality and morbidity by gestational age among infants born at term. Journal of Pediatrics. 2009; 154(3):358-362.

10. Bhutani VK. Developing a systems approach to prevent meconium aspiration syndrome: lessons learned from multinational studies. J Perinatol. 2008 Dec; 28 Suppl 3:S30-5.

11. Naqvi SB, Manzor S. Association of MSAF with perinatal outcome in pregnant women of 37-42 weeks gestation. Pak J Surg 2011; 27(4):292-298.
12. Fischer C, Rybakowski C, Ferdynus C, Sagot $P$, Gouyon JB. A population-based study of meconium aspiration syndrome in neonates born between 37 and 43 weeks of gestation. International Journal of Pediatrics. 2012;e1-7 (321545).

13. Hiersch L, Melamed N, Rosen H, Peled Y, Wiznitzer A, Yogev $Y$. New onset of meconium during labor versus primary meconium-stained amniotic fluid - is there a difference in pregnancy outcome? J Matern Fetal Neonatal Med. 2014 Sep; 27(13):1361-7.

14. Balchin I, Whittaker JC, Lamont RF, Steer PJ. Maternal and fetal characteristics associated with meconiumstained amniotic fluid. Obstet Gynecol. 2011 Apr; $117(4): 828-35$.

15. Hiersch L, Krispin E, Aviram A, Wiznitzer A, Yogev Y, Ashwal $E$. Effect of meconium-stained amniotic fluid on perinatal complications in low-risk pregnancies at term. Am J Perinatol. 2016 Mar; 33(4):378-84.

16. Sori DA, Belete A, Wolde M. Meconium stained amniotic fluid: Factors affecting maternal and perinatal outcomes at Jimma University Specialized Teaching Hospital, South West Ethiopia. Gynecol Obstet (Sunnyvale). 2016; 6:8 (1000394) DOI: 10.4172/2161-0932.1000394.

17. Vaghela HP, Deliwala K, Shah P. Fetal outcome in deliveries with meconium stained liquor. Int J Reprod Contracept Obstet Gynecol. 2014 Dec; 3(4):909-912.

18. Rao KS, Pathapati S, Vansipriya C. Risk factors for meconium stained liquor and outcome of neonate in meconium stained amniotic fluid. Indian Journal of Obstetrics and Gynecology Research 2017; 4(1):1-5.

19. Björkman K, Wesström J. Risk for girls can be adversely affected post-term due to underestimation of gestational age by ultrasound in the second trimester. Acta Obstet Gynecol Scand. 2015 Dec; 94(12):1373-9.

20. Dordević M, Jovanović B, Sazdanović P, Dordević G. Neonate--newborn condition and prematurity with breech delivery. Med Pregl. 2009 Sep-Oct; 62(910):456-60.

21. de Souza A, Minebois H, Luc A, Choserot M, Bertholdt $\mathrm{C}$, Morel $\mathrm{O}$ et al. Stained amniotic fluid and meconium amniotic fluid: Should they change our obstetric management? Gynecol Obstet Fertil Senol. 2018 Jan; 46(1):28-33.

22. Frey HA, Tuuli MG, Shanks AL, Macones GA, Cahill AG. Interpreting category II fetal heart rate tracings: Does meconium matter? Am J Obstet Gynecol. 2014 Dec; $211(6): 644 . e 1-8$. 
23. Alfirevic Z, Aflaifel N, Weeks A. Oral misoprostol for induction of labour. Cochrane Database Syst Rev. 2014 Jun 13; (6):CD001338.

24. Lee KA, Lee SM, Yang HJ, Park CW, Mazaki-Tovi S, Yoon $\mathrm{BH}$ et al. The frequency of meconium-stained amniotic fluid increases as a function of the duration of labor. J Matern Fetal Neonatal Med. $2011 \mathrm{Jul} ;$ 24(7): 880-885.

25. Pariente G, Peles C, Perri ZH, Baumfeld Y, Mastrolia SA, Koifman $A$ et al. Meconium-stained amniotic fluid--risk factors and immediate perinatal outcomes among SGA infants. J Matern Fetal Neonatal Med. 2015 Jun; 28(9):1064-7.

26. Singh SN, Srivastava R, Singh A, Tahazzul M, Kumar $M$, Kanta $C$ et al. Respiratory distress including meconium aspiration syndrome in vigorous neonates born through meconium stained amniotic fluid: Incidence, onset, severity and predictors at birth. Indian J Pediatr. 2013 Jul; 80(7):538-43.

27. Van lerland $Y$, de Boer M, de Beaufort AJ. Meconiumstained amniotic fluid: Discharge vigorous newborns. Arch Dis Child Fetal Neonatal Ed. 2010 Jan; 95(1):F6971.
28. Tybulewicz A, Clegg S, Fonfe G, Stenson B. Preterm meconium staining of the amniotic fluid: Associated findings and risk of adverse clinical outcome. Arch Dis Child Fetal Neonatal Ed. 2004 Jul; 89(4): F328F330.

29. Anwar Z, Butt TK, Kazi MY. Mortality in meconium aspiration syndrome in hospitalized babies. J Coll Physicians Surg Pak. 2011 Nov; 21(11):695-9.

30. Shaikh M, Irfan Waheed KA, Javaid S, Gul R, Hashmi MA, Fatima ST. Detrimental complications of meconium aspiration syndrome and their impact on outcome. J Ayub Med Coll Abbottabad. 2016 Jul-Sep; 28(3):506509.

31. Priyadharshini.V M, Panicker S. Meconium stained liquor and its fetal outcome - retrospective study. IOSR-JDMS. 2013 Mar-Apr; 6(2):27-31.

32. Kumari R, Srichand P, Devrajani BR, Ali Shah SZ, Devrajani T, Bibi l et al. Foetal outcome in patients with Meconium Stained Liquor. J Pak Med Assoc. 2012 May: 62(2); 474-476.

\begin{tabular}{|c|l|l|}
\hline \multicolumn{2}{|c|}{ AUTHORSHIP } & AND CONTRIBUTION DECLARATION \\
\hline Sr. \# & Author(s) Full Name & \multicolumn{1}{|c|}{ Contribution to the paper } \\
\hline 1 & Abeera Choudry & $\begin{array}{l}\text { Design of work Aualysis \& } \\
\text { receiving it critically, Final approval. } \\
\text { Design of work \& Drafting the } \\
\text { article, final approval. } \\
\text { Design of work \& Drafting the } \\
\text { article, final approval. } \\
\text { Design of work \& Drafting the } \\
\text { article, final approval. } \\
\text { Design of work \& Drafting the } \\
\text { article, final approval. } \\
\text { Design of work \& Drafting the } \\
\text { article, final approval. }\end{array}$ \\
\hline 5 & Maria Habib & Syeda Zubda Batool \\
\hline 6 & Uzma Rehman Kallu & Marium Haroon
\end{tabular}

